\title{
Ciência empobrecida e tecnologia de segunda classe
}

JoséLeite Lopes

Aqui estamos reunidos, pela terceira vez, desde que os homens de ciência do Brasil decidiram fundar esta sociedade para, espontâneamente, se encontrarem cada ano, com o objetivo de discutir os problemas que absorvem a vida científica de cada um, rever o progresso de cada setor, debater questôes de interêsse para o desenvolvimento da comunidade científica do país.

Aqui estão matemáticos e sociólogos, físicos e biologistas, químicos, geólogos e engenheiros. Esta sociedade não antepõe barreiras a quem nela deseje ingressar. Mas às suas reuniões, aos seus debates, às suas publicaçôes só comparecem os que tiverem resultados significativos a comunicar. Dos trabalhos e investigações dos especialistas aqui reunidos e dos nossos colegas do país e do exterior, resulta a imagem científica do universo, tal como o compreendemos hoje. Pois o homem de ciência, cujas descobertas são transformadas tão aceleradamente, hoje, em resultados práticos e proveitosos, é antes de tudo o homem que interroga, o curioso que deseja saber de que e como são feitas tôdas as coisas, que provoca a natureza para obter suas respostas. Esta imagem do universo, cujas modificaçôes traduziram a marcha do pensamento religioso e do pensamento filosófico através dos séculos, é hoje uma imagem científica. Além do avanço realizado nos mais variados setores da ciência, vamos encontrar na física a busca dos primeiros princípios, a explicação da estrutura hiperfina da matéria, os misteriosos corpúsculos de que são feitos os sêres e as coisas. Encontramos, lá, as fôrças elementares responsáveis pelas interaçôes entre essas partículas, pelo seu nascimento e por sua morte, por sua transmutação em outros corpúsculos. Aos gregos devemos tanto. Devemos os átomos, simples e indivisíveis, os invisíveis átomos cujos números, configuraçôes e movimentos formariam o nosso mundo. O grande Isaac Newton, que formulou a primeira imagem científica do sistema celeste, e, descobrindo o cálculo infinitesimal, nos legou o mais poderoso instrumento de interpretação matemática da natureza, traduziu assim a sua imagem da estrutura atômica da matéria. "A mim, parece provável que Deus, no Comêço, formou a Matéria de partículas sólidas, maciças, duras,

1. Discurso de abertura da XIII Reunião Anual da SBPC - Poços de Caldas

Texto publicado original mente na revista Ciêncic e Cultura, v. |3, n.3, | $96 \mid$. Reprodução autorizada. 
impenetráveis, móveis, de tais formas e dimensões e com tais outras propriedades e em tal proporção ao Espaço, como é mais conveniente para o fim que Êle as formou"; "Nenhuma fôrça sendo capaz de dividir o que Deus, êle próprio, fềz uno na primeira Criação".

O século que estamos vivendo é justamente o da desintegração nuclear, o das extraordinárias descobertas no domínio da física das altas energias e das partículas elementares. O velho átomo foi quebrado e descobriu-se que êle é formado pela reunião de outras partículas, protons e neutrons no núcleo atômico e de eletrons.

Com a evolução rápida e acelerada das técnicas experimentais da ciência descobriram-se novas partículas sub-atômicas: o hiperons lambda, sigma, csi, os mesons $\mathrm{K}$ e K', os mesons pi e mi, além dos neutrinos e dos fotons - essas imponderáveis partículas da matéria e da luz.

Tal variedade de corpúsculos denominados elementares - estas partículas fundamentais - traz naturalmente consigo inúmeras perguntas e mistérios que tentamos resolver e responder hoje seja nos laboratórios, seja formulando conceitos e esquemas matemáticos.

A imagem científica que hoje possuímos da estrutura da matéria é extraordinàriamente mais rica que a dos gregos. Muitos de nós, entretanto, gostariam ainda de saber, dentre tantas partículas sub-atômicas, se haverá duas ou três partículas, ou classes de partículas, que sejam realmente fundamentais, as demais sendo estruturas compostas das primeiras.

Mas é também possível que o ideal grego de partículas fundamentais da matéria, esgotado que foina teoria atômica, deva ser substituído por outra concepção mais profunda e mais fértil no estado atual do nosso conhecimento e que eu não saberia predizer.

De qualquer modo, eis aí as partículas que conhecemos hoje, as que devem obedecer aos primeiros princípios, aquelas cujas interaçóes e encadeiamento genético formam a base do que vemos.

Eis aí as partículas que não ousarei dizer como Newton "sólidas, maciças, duras, impenetráveis", mas que talvez sejam de tais formas e dimensóes e com tais outras propriedades e em tal proporção ao Espaço...

Gostaria tanto de falar-vos ainda de outras questões - antes para o meu prazer pessoal. Invocando a sabedoria dos deuses, gostaria tanto de dissertar sôbre todos os outros aspectos da imagem científica do universo. Eis uma ambição que me escapa - cada um de nós conhece o especializado setor em que trabalha e investiga, conhece menos os setores afins, conhece mal ou desconhece o que se passa nas demais disciplinas científicas. O que nos salva é que é sempre possível obter uma integração dos principais resultados mais amplos 
de cada setor e formar, para cada um de nós, a reprodução pessoal do quadro científico do universo.

Nesta reunião, trazem-se elementos, contribuiçōes originais para a ciência, para a explicação dos sêres e das coisas.

Mas esta Sociedade não discute apenas as descobertas científicas.

Os homens de ciência do Brasil que a integram não são homens de marfim, não vivem em laboratórios de marfim.

Aqui as mais palpitantes questōes técnicas e científicas de profundo interêsse social têm sido debatidas nas reuniōes anuais e em reuniōes extraordinárias convocadas. Os cientistas que integram esta Sociedade, trabalham em seus laboratórios, procuram, muitas vêzes, com extraordinário desgaste de energia, manter um alto nível de produção científica, mas também sentem - por sentirem na própria carne - as necessidades e dificuldades do país.

Mas nem sempre os caminhos aqui apontados - como dizia o velho geômetra - são do agrado dos reis.

Mencionarei algumas dessas Reunióes extraordinárias: em 1954, sôbre o desenvolvimento da física nuclear no Brasil, em 1956, sôbre a utilização pacífica da energia atômica no Brasil, ainda em 1956, sôbre o regime de tempo integral nas universidades e institutos de pesquisas, em 1957, sôbre universidade e desenvolvimento econômico, em 1958, sôbre o programa de energia atômica brasileira, em 1959, sôbre a ciência, a tecnologia e o papel da COSUPI, em 1960, sôbre a estrutura da projetada Universidade de Brasília.

Dentre as recomendações aprovadas na reunião de 1956 sôbre a utilização da energia atômica no Brasil, lembrarei a de n. 4 que dizia: "é urgente a ampliação, discussão e aperfeiçoamento dos programas atômicos já iniciados incluindo a prospecção e industrialização dos minérios, a produção de materiais nucleares e a instalação de reatores de pesquisa e de potência"; a de n. 5: "é essencial a elaboração de um programa visando a preparação intensiva de físicos, químicos, geólogos, engenheiros nucleares, eletrônicos, matemáticos e outros especialistas nos setores indispensáveis ao desenvolvimento da energia atômica, além de orçamentos adequados e um planejamento que inclua a ampla participação dos cientistas e autoridades universitárias representativas"; a de n. 6 que rezava: "a formação de especialistas a serem utilizados no programa atômico exige um desenvolvimento maior da pesquisa pura em nosso país"; a de n. 8: "recomenda-se a ampla divulgação dos trabalhos, programas e atividades relativas ao programa atômico brasileiro".

No ano de 1957, no documento em que esta Sociedade convocava a IX reunião, para exame do tema "Universidade e desenvolvimento econômico", dizia-se o seguinte: 
"O poder de compulsão das invençôes e descobertas que se vão acumulando e suas potencialidades para aplicação social tanto benéfica quanto nociva, vem reclamando a atenção dos pesquisadores científicos para três ordens de problemas diante dos quais se sentem no dever de pronunciar-se:

1) a contribuição social que estamos capacitados a dar na procura de socluçóes para os problemas humanos, os do nosso povo e os da nossa época;

2) a vigilância permanente que cumpre exercer sôbre a utilização prática das descobertas científicas;

3) os pré-requisitos mínimos para que a atividade científica se possa desenvolver de modo a não apenas refletir, mas a estimular e promover o progresso social”.

"A Sociedade Brasileira para o Progresso da Ciência”, dizia mais adiante, "é, por isto levada a convocar, o mais prontamente possível, uma reunião especial para examinar, dentro desta perspectiva, os obstáculos que presentemente se opõem ao desenvolvimento da ciência no Brasil e que contribuem para o atraso, a pobreza e a insegurança do nosso povo".

"Ciência e tecnologia são, hoje, matéria prima do desenvolvimento econômico e social, mas seu domínio apresenta exigências que precisam ser atendidas se não quisermos correr o risco de comprometer nossas mais legítimas expectativas de progresso".

E quais eram essas exigências proclamadas em 1957 por esta Sociedade?

"1 - Assegurar às universidades e instituiçôes de ensino superior os recursos e as condiçôes necessárias para a formação de pessoal qualificado, em número suficiente para as diversas modalidades de pesquisas científicas e tecnológicas, requeridas pelo desenvolvimento econômico do país;

2 - Estabelecer programas nacionais de desenvolvimento de cada setor de atividade científica e tecnológica, de modo a indicar aquêles campos que estão a exigir maior incentivo e garantir o crescimento homogêneo de todos êles;

3 - Incentivar a criação de institutos de pesquisa junto aos órgãos de ensino superior para assegurar aos estudantes as oportunidades de treinamento indispensáveis à formação de pesquisadores e vincular o ensino superior e a pesquisa científica ao contexto regional em que se assentam;

4 - Estabelecer canais mais francos de comunicação entre as atividades científicas e as atividades econômicas, industriais, agrícolas, pastoris e extrativas, de modo a enriquecer a temática das pesquisas científicas, a vinculá-las melhor aos problemas brasileiros e, igualmente, assegurar ao trabalho dos cientistas o amparo que deverá decorrer do reconhecimento social das contribuições concretas que estão em condições de prestar". 
Estas têm sido algumas das nossas preocupaçôes. Aqui temos estado atentos à ação governamental, através do Conselho Nacional de Pesquisas e da CAPES, apoiando-lhes os bons programas e as boas iniciativas, chamando seus representantes ao debate e ao esclarecimento.

Devem as novas gerações de cientistas conhecer êste acêrvo de luta, de discussão permanente.

As nossas mais legítimas expectativas de progresso exigem uma permanente vigilância, um diálogo que só poderá enriquecer a nossa cultura - são incompatíveis com a indiferença e o comodismo pessoal.

Atravessamos justamente uma fase em que esta vigilância é mais do que nunca exigida desta Sociedade.

Ao lado do desenvolvimento econômico que o país atravessa, os erros e os crônicos defeitos de estrutura do nosso sistema de ensino e, em particular, das Universidades - há muito tempo denunciados por vozes isoladas - começam a ameaçar êsse desenvolvimento, somando-se às inquietaçôes resultantes de erros e crônicos defeitos de certos sistemas sociais arcaicos ainda vigentes em determinadas regiōes do país.

O defeito estrutura das nossas universidades reflete-se na dificuldade de acesso por parte de elementos novos ao corpo docente, o qual se apresenta, em geral, fechado e resistente à renovação e à flexibilidade própria às modernas instituiçôes científicas do mundo. $\mathrm{O}$ ensino, em tais condiçốes, não pode oferecer o rendimento exigido pelos tempos atuai; e a compreensão do fenômeno pelos jovens estudantes conduz ao estado de espírito em que dificilmente se poderá manter a autoridade na estrutura atual.

De tais defeitos, os cientistas são os que mais sofrem. Pois a ciência exige cuidados especiais, laboratórios equipados, grupos de pesquisadores em substituição ao arcaico conceito de cientista isolado. A ciência dá frutos, enriquece a tecnologia, as indústrias, e os homens de emprêsa, mas exige para o pesquisador o ambiente propício à meditação e ao trabalho, exige compreensão. As despesas com a ciência são certamente desprezíveis diante dos grandes lucros que ela proporciona. Já se calculou por acaso o que Faraday gastou em seus laboratórios na Inglaterra e já se comparou com os lucros que já teve e continua a ter a indústria elétrica em todo o mundo?

A reforma da universidade - e do ensino médio - impões-se de tal modo a substituir-lhe a mentalidade antiquada, fechada e temerosa, pelo espírito científico, inquiridor, aberto, renovador, que caracteriza a época que vivemos. Olhai as grandes universidades dos países avançados, será difícil adotar-lhe a estrutura com as indispensáveis modificações impostas pelo país? O que é difícil, o que é realmente impossível é a improvisação de homens competentes. Há que 
buscá-los onde estiverem, sobretudo os que estão em nosso país e colocá-los nas posiçóes que os reclamam.

Uma coisa, entretanto, é fundamental em qualquer reforma: será que se deve confiar aos marechais que perderam uma guerra os planos estratégicos do futuro?

A esta Sociedade compete também denunciar os falsos reformadores, os oportunistas, os promotores da ascensão pessoal., os que pretendem negar o valor da ciência para o Brasil, os que pretendem desenvolver a tecnologia atacando a ciência básica e os cientistas brasileiros, e assim contribuindo para o retardamento da pátria.

O Brasil necessita verdadeiramente de tecnologistas, de escolas e institutos que ensinem e promovam a pesquisa tecnológica. Esta Sociedade, e homens de ciência separadamente vêm pregando esta necessidade. Mas seria absurda e criminosa para êste - e qualquer outro país - a pregação da tecnologia em oposição à ciência. Ambas se complementam. Mas o lugar da ciência básica só poderá ser negado por homens ignorantes ou de má-fé.

Abro o relatório apresentado ao Presidente dos Estados Unidos no ano apssado pela Fundação Nacional de Ciência daquele país. Ali está escrita esta advertência de valor universal. "Não sòmente a segurança da Nação mas o seu bemestar econômico, a excelência de sua vida científica e a qualidade da educação superior Americana estão agora fatalmente ligados ao cuidado com que o Govêrno apóie a pesquisa. Se êste apôio fôr hesitante e errático, se der ênfase a mecanismos e utensílios com desprêzo da compreensão fundamental, se esbanjar dinheiro em alguns domínios populares e deixar outros, importantes, à morte, se deixar de encorajar homens excepcionais e programas excepcionais, o resultado liquido poderá ser uma ciência empobrecida e uma tecnologia de segunda classe".

É precisamente uma tecnologia de segunda classe, a que está pregando o Sr. Oliveira Júnior, presidente da COSUPI, órgão do Ministério da Educação, "cândidamente envolvido na transparente indumentária da salvação pública, mas na realidade", segundo o órgão oficial desta Sociedade, de março do corrente ano, "instrumento poderoso nas mãos de um único indivíduo, dotado daquelas qualidades necessárias para utilizar a linguagem demagógica de aventureiros, com a qual consegue convencer aqueles homens desinteressados do Govêrno para a mobilização de bilhôes de cruzeiros, no mais insensato e descabido plano de construir institutos científicos, com uma simples penada, e publicação compulsória no Diário Oficial da União".

"E de uma só vez cria 14 Institutos, sem plano, sem assessoria técnica, sem critério, mas com muito, muito dinheiro. Isso numa época em que o Conselho Nacional de Pesquisas morria à mingua de recursos financeiros e a CAPES se vê 
ameaçada de sumária eliminação do rol das instituições de amparo à ciência.

Em contraste com essa situação de miséria e angústia... um único homem, o Sr. Presidente do COSUPI, dispondo de três auxiliares de escritório, vangloria-se de vir a público proclamar que as suas dotaçôes orçamentárias cresceram vertiginosamente na seguinte escala: 230 milhões de cruzeiros 590 milhôes de cruzeiros 915 milhôes de cruzeiros 1.080 milhões de cruzeiros

Total 2.815 bilhōes de cruzeiros

Com êsse programa "O céu é o limite", o Sr. Oliveira Júnior sente-se suficientemente seguro para desfechar o mais grosseiro e indecoroso libelo jamais escrito contra a ciência básica e os cientistas brasileiros.

Um homem só em 4 anos gasta 2.815 bilhões de cruzeiros em programas ditos de desenvolvimento de institutos desprezando a opinião dos cientistas brasileiros, atacando-os como o fêz, ao mesmo tempo que diz estas afirmações espantosas: "O Brasil não é pobre por falta da chamada ciência pura. Essa existe por aí, em larga escala (!), publicada em livros, em compêndios e em revistas de todo o tipo".

É êste homem dos bilhões que afirma: "não se compreende que a maioria dos recursos que a Nação emprega em pesquisas, sejam desviados para investigações que apenas interessam à fome de saber de seus autores e constituem, quase sempre, a duplicação de pesquisas que estão sendo levadas a efeito em países mais ricos, em laboratórios e em organizações que dispõem de recursos com os quais não podemos sequer sonhar em nosso atual estágio de desenvolvimento econômico".

O que tudo isso torna evidente é que não existiu - como não existe ainda uma política científica nacional, adotada pelo Govêrno Federal e que, entrosando os diversos organismos de estímulo à pesquisa científica e tecnológica e à educação científica universitária, seja capaz de assegurar o desenvolvimento harmonioso que desejamos.

O atual Govêrno da República já tomou iniciativas do maior interêsse para o desenvolvimento da pesquisa científica e da cultura dêste país: prestigiou o Conselho Nacional de Pesquisas reforçando-lhe a dotação para o corrente ano, pediu desse órgão a elaboração de um programa quinquenal, capaz de prever as necessidades e o desenvolvimento das pesquisas científicas nos próximos cinco 
anos; criou o Conselho Nacional de Cultura; determinou os estudos necessários à reforma da atual estrutura universitária; designou um cientista, membro dos mais ilustres desta Sociedade, para a Assessoria Técnica da Presidência da República.

Ousamos, entretanto, sugerir a necessidade de outras medidas paralelas para que não se percam, nem se entravem em escalóes inferiores da Administração, tais iniciativas. O caso da COSUPI, que gasta bilhôes, constitui flagrante tumulto ao programa do Conselho Nacional de Pesquisas e da CAPES.

O artigo publicado no Jornal do Comércio do Rio de Janeiro, de 12-3-61, pelo atual Vice-Presidente do Conselho Nacional de Pesquisas, o Dr. Antônio Moreira Couceiro, traduz fielmente o pensamento de muitos de seus colegas desta Sociedade.

A reforma da universidade, em estudo, creio eu, pelo Conselho Nacional de Cultura, deveria também receber sugestões dos nossos cientistas, sobretudo no que se refere aos modernos métodos de formação científica, bem como à nova estrutura. Essa reforma deverá entrosar-se com uma reforma correspondente do ensino médio e primário, visando de um lado a adaptar o primeiro à nova fase de desenvolvimento do país, e, no segundo, a reduzir dràsticamente o índice de analfabetismo no país.

Tantos são os problemas e tantos serão os debates nesta Reunião que, estou certo, conduzirão a úteis sugestões às autoridades superiores da República.

Mas aqui nos reunimos primordialmente para impulsionar a ciência e não devemos exagerar a nossa preocupação por algumas pessoas que, ofuscadas pelos espetaculares inventos tecnológicos de países avançados, se esquecem dos trabalhos de laboratório e meditação que deram lugar a tais descobertas. Essas pessoas passarão, por anti-históricas. Permanecerá inapagável a contribuição à humanidade de homens como vós, que trabalham movidos por uma necessidade interior.

Justamente com os escritores, os poetas, os pintores, os criadores da música, constituem os homens de ciência a mais preciosa riqueza de uma Nação. Condenado seria o Govêrno que, de um país, desprezasse os sábios, os santos e os heróis.

O Brasil, entretanto, cresce e nos estimula ao trabalho. 